\title{
Anemia at pediatric intensive care unit discharge: prevalence and risk markers
}

\author{
Pierre Demaret ${ }^{1,2^{*}} \mathbb{D}$, Oliver Karam ${ }^{3,4} \odot$, Marisa Tucci ${ }^{5}$, Jacques Lacroix ${ }^{5}$, Hélène Behal ${ }^{6}$, Alain Duhamel ${ }^{6}$, \\ Frédéric Lebrun ${ }^{1}$, André Mulder ${ }^{1}$ and Stéphane Leteurtre ${ }^{2,7}$
}

\begin{abstract}
Background: Anemia is prevalent at pediatric intensive care unit (PICU) admission and incident during PICU stay, but little is known about anemia at PICU discharge. Anemia after critical illness is an important issue because it could impact post-PICU outcome. We aimed to estimate the prevalence of anemia at PICU discharge and to determine its risk markers.

Methods: This is an ancillary study of a prospective observational study on transfusion practices conducted in the PICU of a tertiary care children's hospital. All children consecutively admitted to the PICU during a 1-year period were considered for inclusion. Data were prospectively collected from medical charts, except for hemoglobin (Hb) levels at PICU and hospital discharge that were collected retrospectively. Anemia was defined by an $\mathrm{Hb}$ concentration below the lower limit of the normal range for age.

Results: Among the 679 children retained for analysis, 390 (57.4\%) were anemic at PICU discharge. After multivariate adjustment, anemia at PICU admission was the strongest risk marker of anemia at PICU discharge. The strength of this association varied according to age (interaction): The odds ratio $(\mathrm{OR})(95 \% \mathrm{Cl})$ of anemia at PICU discharge was 4.85 (1.67-14.11) for 1-5-month-old infants anemic versus not anemic at PICU admission, and it was $73.13(13.43,398.19)$ for adolescents anemic versus not anemic at PICU admission. Children admitted after a non-cardiac surgery had an increased risk of anemia at PICU discharge [OR $2.30(1.37,3.88), p=0.002]$. The proportion of anemic children differed between age categories, while the median $\mathrm{Hb}$ level did not exhibit significant variations according to age.
\end{abstract}

Conclusions: Anemia is highly prevalent at PICU discharge and is strongly predicted by anemia at PICU admission. The usual age-based definitions of anemia may not be relevant for critically ill children. The consequences of anemia at PICU discharge are unknown and deserve further scrutiny.

Keywords: Child, Anemia, Erythrocyte, Pediatric intensive care unit, Pediatric, Outcome

\section{Background}

Anemia, defined as a concentration of hemoglobin $(\mathrm{Hb})$ below the lower limit of the normal range for age (Table 1) [1], is a common issue in critically ill patients: Approximately two-thirds of critically ill adults are anemic at admission to the intensive care unit (ICU) $[2,3]$ and up to $98 \%$ of them have been reported to be anemic by ICU day 8 [4]. Anemia is frequent in pediatric ICU (PICU) as well: In a large North American multicenter

\footnotetext{
*Correspondence: pierre.demaret@chc.be

1 Pediatric Intensive Care Unit, Department of Pediatrics, CHC, Liège, Belgium

Full list of author information is available at the end of the article
}

study, one-third of the critically ill children with a PICU stay of at least 2 days were anemic at PICU admission and an additional $40 \%$ became anemic during their PICU stay [5].

Given the high prevalence and incidence of anemia at admission and during ICU stay and given that red blood cell (RBC) transfusion guidelines recommend a restrictive strategy for most critically ill patients $[6,7]$, it makes sense to wonder about anemia at ICU discharge.

There are scarce data, suggesting that about $85 \%$ of adults are anemic when leaving the ICU $[8,9]$ and that this anemia persists for weeks, most of the patients still being anemic at hospital discharge [9]. It even seems 
Table 1 Hemoglobin thresholds used to diagnose anemia and anemia prevalence at PICU discharge

\begin{tabular}{llc}
\hline Age & $\begin{array}{l}\text { Hb threshold to diag- } \\
\text { nose anemia }(\mathbf{g} / \mathbf{L})\end{array}$ & $\begin{array}{l}\text { Proportion of patients } \\
\text { anemic at PICU discharge } \\
\text { in our study }\end{array}$ \\
\hline$<1$ month & $<130$ & $39 / 55(70.9)$ \\
1-5 months & $<95$ & $32 / 105(30.5)$ \\
6-59 months & $<110$ & $125 / 231(54.1)$ \\
5-11 years & $<115$ & $70 / 119(58.8)$ \\
12-14 years & $<120$ & $55 / 81(67.9)$ \\
$\geq 15$ years & & $39 / 46(84.8)$ \\
Female & $<120$ & $30 / 42(71.4)$ \\
Male & $<130$ & $390 / 679(57.4)$ \\
Total & &
\end{tabular}

a Number of anemic children/total number of children in the age category (\%) $\mathrm{Hb}$ hemoglobin, $\mathrm{PICU}$ pediatric intensive care unit

that up to half of adults leaving the ICU with a $\mathrm{Hb}$ level $<100 \mathrm{~g} / \mathrm{L}$ are still anemic 6 months after hospital discharge [10].

Data about anemia at PICU discharge are almost nonexistent. In a single-center Canadian study with large exclusion criteria and no cases of cardiac surgery, 94/392 (24\%) children were discharged from PICU with anemia [11]. No other pediatric study on this topic has been published so far.

Anemia is far from trivial and is associated with worse outcomes even in non-critically ill patients. For example, anemia is associated with mortality in African children and a recent meta-analysis of nearly 12,000 children showed that the risk of death falls by $24 \%$ for each $1 \mathrm{~g} / \mathrm{dL}$ increase in $\mathrm{Hb}$ [12]. Anemia is associated with neurological outcome. For example, prenatal iron deficiency anemia is associated with a worse mental development of the child at 12, 18 and 24 months of age [13], and a lower mean $\mathrm{Hb}$ after a hypoxic-ischemic brain injury following cardiac arrest is associated with a higher odd of unfavorable neurological outcome at hospital discharge [14]. Anemia is also associated with a decreased quality of life and with an increase in healthcare resource utilization $[15,16]$.

These associations between anemia and worse outcomes explain why the question of anemia after critical illness is of high importance. If anemia is frequent at PICU discharge, then it could play an important role in the post-PICU course.

Outcome after discharge from intensive care is a real challenge for PICU physicians. Mortality rates in PICU are very low (2.4\%) as recently reported [17]. Cognitive impairments and physical impairments are currently recognized as potential post-intensive care morbidities of importance [18], and anemia may have an impact on both of them. Limited adult data indicate that patients discharged from ICU with anemia may have a reduced health-related quality of life as compared to the normal population and to non-selected ICU survivors [10]. To our knowledge, no pediatric data have been published so far on this issue.

The first step in assessing the role of anemia at PICU discharge is to determine its prevalence, which is currently unknown. We therefore conducted a study aiming to determine the prevalence of anemia at PICU discharge and its risk markers.

\section{Methods \\ Study design, study site and population}

This study is a post hoc analysis of a single-center prospective database aiming to describe transfusion practices in PICU $[19,20]$.

The PICU of Sainte-Justine University Hospital is a multidisciplinary PICU, serving both medical and surgical specialties. All consecutive admissions to PICU, from April 21, 2009, to April 20, 2010, were prospectively screened for recruitment. A priori defined exclusion criteria were: newborn with gestational age less than 40 weeks at the time of PICU admission, age less than 3 days or more than 18 years at PICU admission, pregnancy or admission just after labor. We excluded a posteriori all children with no $\mathrm{Hb}$ level at PICU discharge (as defined below).

\section{Primary outcome}

We retrospectively collected the $\mathrm{Hb}$ level at discharge from PICU, defined as follows: the $\mathrm{Hb}$ level closest to PICU discharge, collected on a complete blood count after PICU admission and not more than 7 days prior to PICU discharge.

Based on the World Health Organization (WHO) criteria for children aged 6 months and older [21] and on the thresholds proposed in a pediatric textbook for infants younger than 6 months of age [22], we defined anemia as a $\mathrm{Hb}$ level $<130 \mathrm{~g} / \mathrm{L}$ for neonates, $<95 \mathrm{~g} / \mathrm{L}$ for 1-5-month-old infants, < $110 \mathrm{~g} / \mathrm{L}$ for 6-59-month-old children, < $115 \mathrm{~g} / \mathrm{L}$ for 5-11-year-old children, < $120 \mathrm{~g} / \mathrm{L}$ for 12-14-year-old infants, < $120 \mathrm{~g} / \mathrm{L}$ for female adolescents aged $\geq 15$ years and $<130 \mathrm{~g} / \mathrm{L}$ for male adolescents aged $\geq 15$ years (Table 1 ).

\section{Data collection}

Trained research assistants prospectively collected data daily in a validated case report form. All information was abstracted from medical charts.

Patient characteristics and baseline data collected within $24 \mathrm{~h}$ after PICU admission included age, gender, medical past and admission diagnoses. (More than one diagnosis could be attributed to each patient.) A 
predictive score of mortality, the Pediatric Risk of Mortality (PRISM score, first version) [23], and a descriptive score of severity of multiple organ dysfunction, the Pediatric Logistic Organ Dysfunction (PELOD score, first version) [24], were used to describe severity of illness at PICU admission.

Several data were prospectively collected during the entire PICU stay. Organ dysfunctions and multiple organ dysfunction syndrome (MODS) were defined according to Goldstein et al. [25]. New MODS was diagnosed if a patient with no organ dysfunction or one organ dysfunction at the time of PICU admission developed two or more organ dysfunctions during PICU stay or if he/she died; progressive MODS was diagnosed if a patient who already had MODS at PICU admission developed dysfunction of at least one other organ during PICU stay or if he/she died. Infections were recorded as per medical notes in the patient chart and by following up all cultures done during PICU stay. Severe sepsis and septic shock were defined according to the definitions published by an International Pediatric Sepsis Consensus Conference [25]. Use of extracorporeal support techniques as well as mortality (death in PICU and in hospital) and the length of stay in PICU and in hospital were recorded.

The $\mathrm{Hb}$ concentration at hospital discharge was collected retrospectively and was defined as the $\mathrm{Hb}$ level closest to hospital discharge, collected after PICU discharge, but not more than 7 days prior to hospital discharge.

Institutional review board approval was obtained for the collection of the initial database, waiving the requirement for written informed consent due to the observational nature of the study.

\section{Statistical analysis}

Quantitative variables were expressed as mean (standard deviation) if the variable was normally distributed (as assessed graphically and by using the Shapiro-Wilk test) and as median (interquartile range) if not. Qualitative variables were expressed as frequencies and percentages.

Association between anemia at PICU discharge and each patient characteristic at PICU admission or during PICU stay was first studied by bivariate analysis using a logistic regression with a random subject effect (general linear mixed model, GLMM) that allowed us to account for the occurrence of repeated measures per subject (no more than two admissions per subject).

In order to identify independent risk markers of anemia at PICU discharge, we performed multivariable GLMM analysis using the following steps: First, the variables with a $p$ value less than 0.2 in bivariate analysis were introduced in a multivariable GLMM. The PRISM score was forced into the model, as we wanted to adjust for the severity of disease. Second, a backward selection at level 0.1 was performed to simplify the model by eliminating variables that were useless in the model. Third, considering the subset of variables selected at the previous step, all the possible first-order interactions were tested in bivariate models. The final multivariable GLMM was obtained by considering the variables selected at the second step and the interactions having a significant level less than 0.1 .

\section{Results}

Over the 1-year study period, there were 913 consecutive PICU admissions; 71 cases were excluded according to a priori criteria and 163 cases were excluded due to a posteriori criteria (Fig. 1). This left 679 cases for analysis. Children excluded a posteriori differed from those included: They were older (median age (IQR) 53 (12-155) versus 39 (6-141) months, $p=0.019)$, were less severely ill (median admission PRISM score $4(0-6)$ versus 5 (2-9), $p<0.001)$, had less congenital heart disease $(8.6 \%$ versus $23.1 \%, p<0.001)$ and had a higher median $\mathrm{Hb}$ at PICU admission (122 (108-139) versus 110 (95-124) g/L, $p<0.001)$.

\section{Hemoglobin and anemia at PICU discharge}

Among the 679 cases retained for analysis, 390 (57.4\%) were anemic at PICU discharge. The last Hb before PICU discharge was collected on the day of PICU discharge for $543(80 \%)$ children, 1 day before PICU discharge for 85 (12.5\%) children and 2, 3, 4, 5, 6 and 7 days before PICU discharge for 25 (3.7\%), 11 (1.6\%), 5 (0.7\%), 6 (0.9\%), 3 $(0.4 \%)$ and $1(0.1 \%)$ children, respectively. The median $\mathrm{Hb}$ (IQR) at PICU discharge was $96 \mathrm{~g} / \mathrm{L}(86-106)$ in anemic children and $122 \mathrm{~g} / \mathrm{L}$ (113-133) in non-anemic children $(p<0.001)$ (Fig. 2a). The proportion of anemic children was higher in neonates $(70.9 \%)$ and adolescents (male $71.4 \%$, female $84.8 \%$ ), while it was lower in infants aged 1-5 months (30.5\%) (Table 1, Fig. 3).

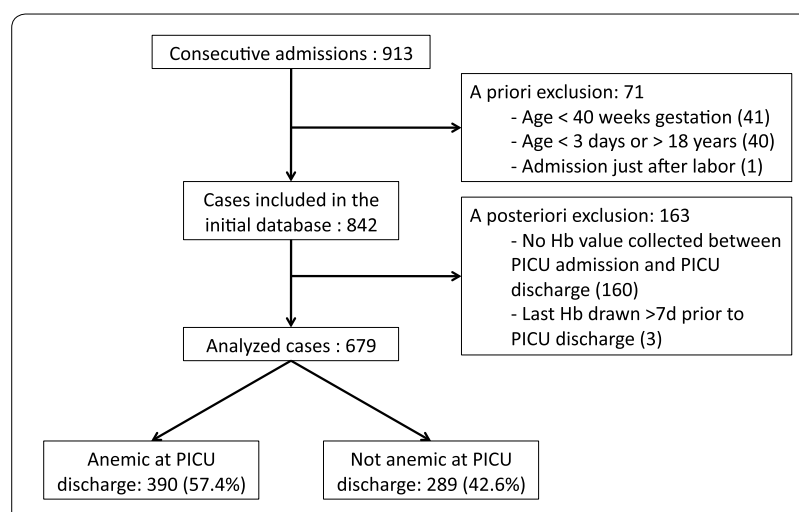

Fig. 1 Flowchart of study patients. PICU pediatric intensive care unit 

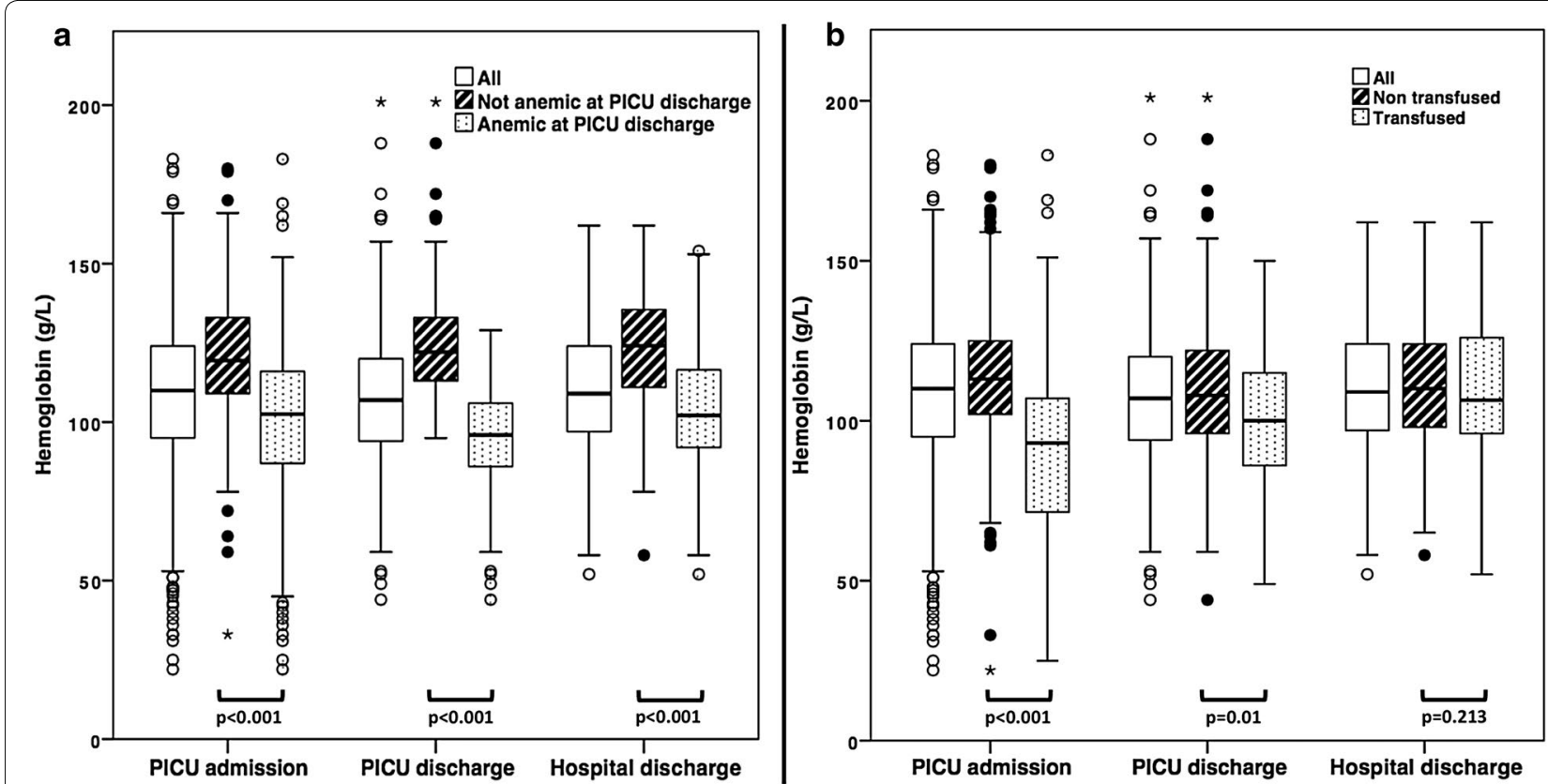

Fig. 2 Whisker plots of the hemoglobin level at PICU admission, PICU discharge and hospital discharge for children anemic and non-anemic at PICU admission (a) and for children transfused and non-transfused during their PICU stay (b). PICU pediatric intensive care unit; points and asterisks represent outliers and extreme outliers, respectively

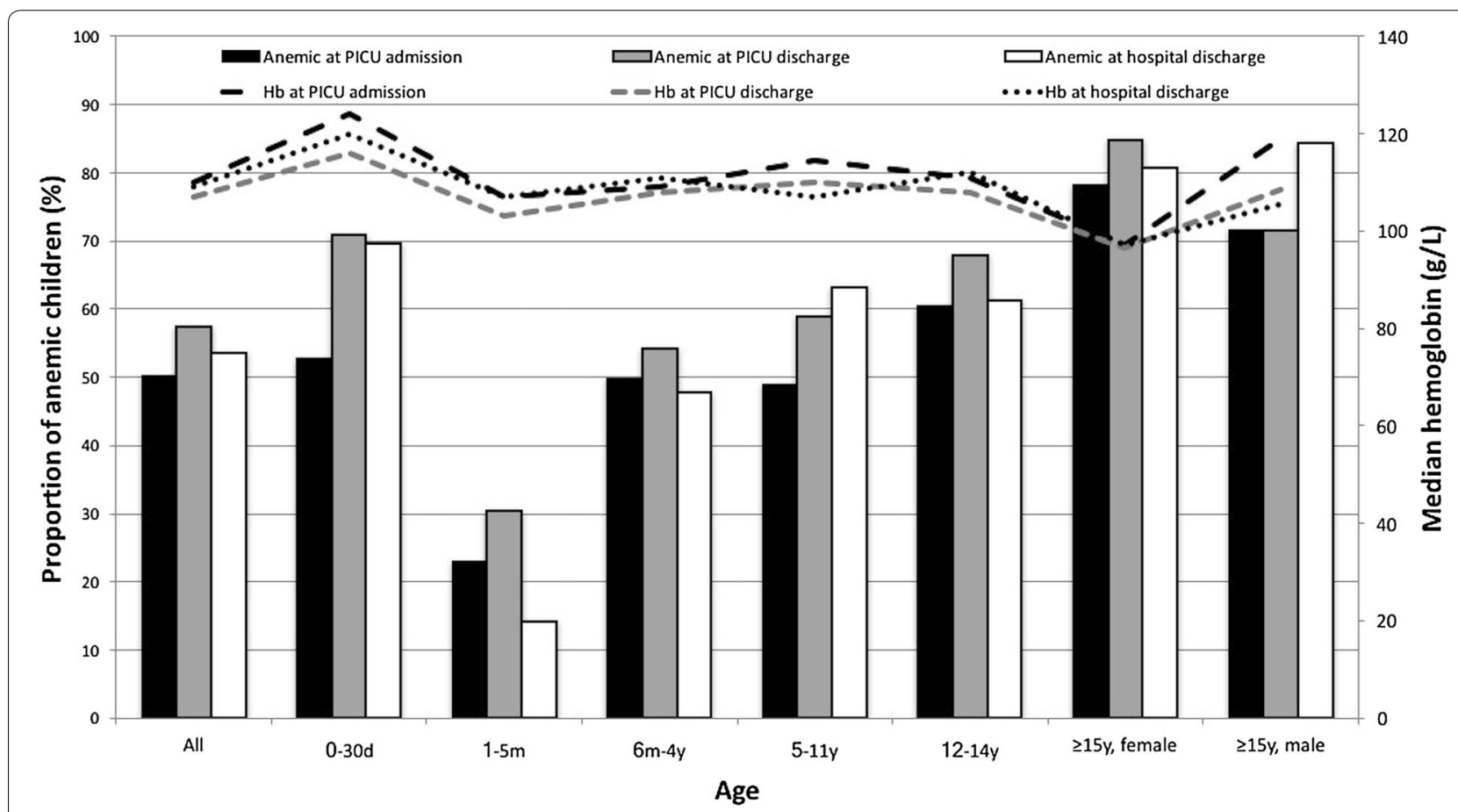

Fig. 3 Double Y-axis graph on the proportion of anemic children at PICU admission, PICU discharge and hospital discharge according to age, and median $\mathrm{Hb}$ level at PICU admission, PICU discharge and hospital discharge according to age. Hb hemoglobin, PICU pediatric intensive care unit

Bivariate association between patient, PICU admission or PICU stay characteristics and anemia at PICU discharge Children anemic at PICU discharge were older than non-anemic children, and they were more likely to suffer from a cancer and less likely to have cyanotic congenital heart disease (Table 2). Children with a higher admission 
Table 2 Bivariate association between patient and PICU stay characteristics and anemia at PICU discharge

\begin{tabular}{|c|c|c|c|c|c|}
\hline & All patients $(n=679)$ & Not anemic $(p=289)$ & Anemic $(n=390)$ & Crude OR $\left(\mathrm{Cl}_{95 \%}\right)$ & $p$ value \\
\hline \multicolumn{6}{|l|}{ Patient characteristics } \\
\hline Age (months) & $39(6-141)$ & $20(4-89)$ & $57.5(10.8-159.3)$ & & $<0.001$ \\
\hline$<1$ month & $55(8.1)$ & $16(5.4)$ & $39(10.0)$ & Reference & \\
\hline $1-5$ months & $105(15.5)$ & $73(25.3)$ & $32(8.2)$ & $0.18(0.09,0.38)$ & \\
\hline 6-59 months & $231(34.0)$ & $106(36.7)$ & $125(32.1)$ & $0.48(0.25,0.94)$ & \\
\hline $5-11$ years & $119(17.5)$ & $49(17.0)$ & $70(17.9)$ & $0.59(0.29,1.20)$ & \\
\hline $12-14$ years & $81(11.9)$ & $26(9.0)$ & $55(14.1)$ & $0.86(0.40,1.88)$ & \\
\hline$\geq 15$ years & $88(13.0)$ & $19(6.6)$ & $69(17.7)$ & $1.47(0.66,3.30)$ & \\
\hline Gender male & $353(52.0)$ & $147(50.9)$ & $206(52.8)$ & $1.08(0.78,1.50)$ & 0.62 \\
\hline Cancer $(n, \%)$ & $37(5.4)$ & $10(3.5)$ & $27(6.9)$ & $2.08(0.99,4.37)$ & 0.048 \\
\hline Congenital heart disease $(n, \%)$ & & & & & 0.018 \\
\hline Cyanotic & $84(12.4)$ & $49(17.0)$ & $35(9.0)$ & $0.49(0.29,0.80)$ & \\
\hline Non-cyanotic & $73(10.8)$ & $29(10.0)$ & $44(11.3)$ & $1.04(0.61,1.77)$ & \\
\hline No congenital heart disease & $522(76.9)$ & $211(73.0)$ & $311(79.7)$ & Reference & \\
\hline \multicolumn{6}{|l|}{ PICU admission day } \\
\hline PRISM score & & & & & 0.35 \\
\hline$>10$ & $125(18.4)$ & $53(18.3)$ & $72(18.5)$ & $0.84(0.48,1.46)$ & \\
\hline $6-10$ & $194(28.6)$ & $93(32.2)$ & $101(25.9)$ & $0.67(0.40,1.11)$ & \\
\hline $1-5$ & $250(36.8)$ & $101(34.9)$ & $149(38.2)$ & $0.91(0.56,1.48)$ & \\
\hline 0 & $110(16.2)$ & $42(14.6)$ & $68(17.4)$ & Reference & \\
\hline PELOD score & & & & & 0.034 \\
\hline$>20$ & $27(4.0)$ & $7(2.4)$ & $20(5.1)$ & $2.82(1.09,7.29)$ & \\
\hline $11-20$ & $153(22.5)$ & $56(19.4)$ & $97(24.9)$ & $1.71(1.1,2.67)$ & \\
\hline $1-10$ & $271(39.9)$ & $113(39.1)$ & $158(40.5)$ & $1.39(0.95,2.03)$ & \\
\hline 0 & $228(33.6)$ & $113(39.1)$ & $115(29.5)$ & Reference & \\
\hline Lowest $\mathrm{Hb}(\mathrm{g} / \mathrm{L})$, mean $\pm \mathrm{SD}$ & $108.9 \pm 24.3$ & $120.8 \pm 20.1$ & $100.4 \pm 23.4$ & $0.96(0.95,0.96)$ & $<0.001$ \\
\hline Anemia & $341(50.2)$ & $57(21.1)$ & $284(75.1)$ & $11.27(7.63,16.65)$ & $<0.001$ \\
\hline Lowest platelets count $\left(\times 10^{9} / \mathrm{L}\right)$, mean $\pm \mathrm{SD}$ & $234.5 \pm 133.9$ & $250.2 \pm 114.6$ & $223.2 \pm 145.2$ & $0.98(0.97,0.99)$ & 0.021 \\
\hline Thrombocytopenia $^{\mathrm{a}}$ & $194(28.6)$ & $63(23.4)$ & $131(34.7)$ & $1.72(1.18,2.5)$ & 0.005 \\
\hline \multicolumn{6}{|l|}{ Admission diagnosis } \\
\hline Respiratory disease & $239(35.2)$ & $127(43.9)$ & $112(28.8)$ & $0.51(0.36,0.72)$ & $<0.001$ \\
\hline Infection & $254(37.5)$ & $120(41.5)$ & $134(34.4)$ & $0.74(0.53,1.04)$ & 0.079 \\
\hline Non-cardiac surgery & $165(24.3)$ & $48(16.7)$ & $117(30.2)$ & $2.16(1.44,3.21)$ & $<0.001$ \\
\hline Cardiac surgery & $106(15.6)$ & $47(16.3)$ & $59(15.1)$ & $0.91(0.59,1.42)$ & 0.69 \\
\hline Seizures & $49(7.2)$ & $27(9.3)$ & $22(5.6)$ & $0.58(0.31,1.07)$ & 0.081 \\
\hline Any shock & $46(6.8)$ & $16(5.6)$ & $30(7.7)$ & $1.44(0.74,2.79)$ & 0.28 \\
\hline Trauma & $23(3.4)$ & $19(4.9)$ & $4(1.4)$ & $3.62(1.17,11.26)$ & 0.027 \\
\hline \multicolumn{6}{|l|}{ PICU stay } \\
\hline \multicolumn{6}{|l|}{ Transfusion $(n, \%)$} \\
\hline Any transfusion & $176(25.9)$ & $59(20.4)$ & $117(30.0)$ & $1.67(1.14,2.45)$ & 0.009 \\
\hline Red blood cells & $143(21.1)$ & $45(15.6)$ & $98(25.1)$ & $1.83(1.21,2.77)$ & 0.005 \\
\hline Plasma & $94(13.8)$ & $39(13.5)$ & $55(14.1)$ & $1.06(0.66,1.7)$ & 0.81 \\
\hline Platelets & $58(8.5)$ & $13(4.5)$ & $45(11.5)$ & $2.73(1.4,5.32)$ & 0.004 \\
\hline Respiratory dysfunction & $337(49.6)$ & $159(55.0)$ & $178(45.6)$ & $0.69(0.5,0.95)$ & 0.025 \\
\hline Cardiovascular dysfunction & $14(2.1)$ & $4(1.4)$ & $10(2.6)$ & $1.91(0.56,6.55)$ & 0.30 \\
\hline Hematological dysfunction & $115(16.9)$ & $32(11.1)$ & $83(21.3)$ & $2.15(1.35,3.42)$ & 0.002 \\
\hline Neurological dysfunction & $388(57.1)$ & $162(56.1)$ & $226(57.9)$ & $1.09(0.79,1.51)$ & 0.60 \\
\hline Hepatic dysfunction & $98(14.4)$ & $33(11.4)$ & $65(16.7)$ & $1.55(0.97,2.5)$ & 0.069 \\
\hline Renal dysfunction & $24(3.5)$ & $4(1.4)$ & $20(5.1)$ & $3.86(1.25,11.95)$ & 0.02 \\
\hline
\end{tabular}


Table 2 continued

\begin{tabular}{|c|c|c|c|c|c|}
\hline & All patients $(n=679)$ & Not anemic $(p=289)$ & Anemic $(n=390)$ & Crude OR $\left(\mathrm{Cl}_{95 \%}\right)$ & $p$ value \\
\hline New or progressive MODS & $112(16.5)$ & $43(14.9)$ & $69(17.7)$ & $1.22(0.78,1.89)$ & 0.38 \\
\hline Death in PICU & $25(3.7)$ & $9(3.1)$ & $16(4.1)$ & $1.35(0.56,3.24)$ & 0.50 \\
\hline Infection (proven or suspected) & $301(44.3)$ & $137(47.6)$ & $164(42.3)$ & $0.81(0.58,1.12)$ & 0.20 \\
\hline Severe sepsis/septic shock & $63(9.3)$ & $19(6.6)$ & $44(11.3)$ & $1.8(1.00,3.26)$ & 0.051 \\
\hline \multicolumn{6}{|l|}{ Support techniques $(n, \%)$} \\
\hline Mechanical ventilation & $350(51.5)$ & $147(50.9)$ & $203(52.1)$ & $1.05(0.76,1.45)$ & 0.75 \\
\hline Duration (day), median (Q1-Q3) ${ }^{\mathrm{b}}$ & $2(1-5)$ & $2(1-5)$ & $3(1-5)$ & & \\
\hline ECMO/Berlin heart & $8(1.2)$ & $4(1.4)$ & $4(1.0)$ & $0.74(0.17,3.24)$ & 0.68 \\
\hline Plasmapheresis & $5(0.7)$ & $1(0.3)$ & $4(1.0)$ & - & - \\
\hline Renal replacement therapy & $13(1.9)$ & $1(0.3)$ & $12(3.1)$ & $9.12(1.11,75.09)$ & 0.04 \\
\hline PICU length of stay (day), median (Q1-Q3) & $3(2-6)$ & $3(2-6)$ & $3(2-6)$ & & 0.70 \\
\hline PICU stay > $48 \mathrm{~h}(n, \%)$ & $450(66.3)$ & $185(64.0)$ & $265(67.9)$ & $1.2(0.85,1.68)$ & 0.30 \\
\hline
\end{tabular}

Values are frequencies and percentage unless otherwise specified

$O R$ odds ratio, PICU pediatric intensive care unit, $P R I S M$ pediatric risk of mortality, $P E L O D$ pediatric logistic organ dysfunction, $H b$ hemoglobin, SD standard deviation, MODS multiple organ dysfunction syndrome, ECMO extracorporeal membrane oxygenation, $C I$ confidence interval

a Odds ratio calculated for an increase of $10 \times 10^{9} / \mathrm{L}$

b Calculated for patients mechanically ventilated only

c Mann-Whitney U test was used for this variable due to its distribution

PELOD score showed an increased risk of anemia at PICU discharge as well as those admitted after non-cardiac surgery or due to trauma.

Anemia and thrombocytopenia at PICU admission were significantly associated with anemia at PICU discharge (OR (95\% CI) 11.27 (7.63, 16.65), $p<0.001$, and 1.72 (1.18, 2.50), $p=0.005$, respectively). $\mathrm{RBC}$ and platelet transfusions during PICU stay were associated with an increased risk of anemia at PICU discharge (OR 1.83 (1.21, 2.77), $p=0.005$, and $2.73(1.4,5.32$ ), $p=0.004$, respectively), but plasma transfusions were $\operatorname{not}(p=0.81)$.

\section{Incidence of anemia after PICU admission}

$\mathrm{Hb}$ at PICU admission was available for 648 children. Among the 307 (49.8\%) children not anemic at PICU admission, 94 (30.6\%) were anemic at PICU discharge. These 94 children accounted for one quarter (94/390, 24.1\%) of the children anemic at PICU discharge.

$\mathrm{Hb}$ levels at PICU admission, PICU discharge and hospital discharge were available in 372 children. Among the 139 (37.4\%) children not anemic at PICU admission, 38 (27.3\%) became anemic during PICU stay and 19 (13.7\%) became anemic during the hospital stay after PICU discharge; 38 (27.3\%) were still anemic at hospital discharge.

\section{Multivariable analysis}

The adjusted association between anemia at PICU admission and anemia at PICU discharge varied according to age (interaction): The strongest association was for adolescents aged 12-14 years (adjusted OR 33.44 (7.91,
Table 3 Multivariable analysis: risk markers of anemia at PICU discharge

\begin{tabular}{lcc}
\hline & Adjusted $\mathbf{O R}\left(\mathbf{C l}_{\mathbf{9 5}} \mathbf{\%}\right)$ & $\boldsymbol{p}$ value \\
\hline Anemia at PICU admission $\times$ age & & 0.056 \\
Anemia at PICU admission $^{\mathrm{a}}$ & & \\
$<1$ month & $9.32(1.99,43.75)$ & \\
$1-5$ months & $4.85(1.67,14.11)$ & \\
6 months-4 years & $6.79(3.58,12.91)$ & \\
$5-11$ years & $9.13(3.57,23.37)$ & \\
$12-14$ years & $33.44(7.91,141.33)$ & \\
$\geq 15$ years & $73.13(13.43,398.19)$ & \\
Non-cardiac surgery & $2.30(1.37,3.88)$ & 0.002 \\
Renal dysfunction & $3.19(0.85,11.92)$ & 0.083 \\
\hline
\end{tabular}

$O R$ odds ratio, $P I C U$ pediatric intensive care unit, $C l$ confidence interval

${ }^{\text {a }}$ For each age category, children anemic at PICU admission are compared to non-anemic children (reference group)

141.33)) and $\geq 15$ years (adjusted OR 73.13 (13.43, 398.19)), while the lowest association was for infants aged 1-5 months (adjusted OR $4.85(1.67,14.11)$ ) (Table 3). Non-cardiac surgery was an independent risk marker of anemia at PICU discharge (OR 2.30 (1.37, 3.88), $p=0.002)$ as well. Renal dysfunction was retained in the final multivariable model, but its association with anemia at PICU discharge was not statistically significant. Admission PRISM score was forced into the multivariate model, but it was not statistically associated with anemia at PICU discharge $(p=0.62)$. All the other variables included in the multivariate analysis were not retained 
in the final model after backward selection (cancer; congenital heart disease; thrombocytopenia at PICU admission; admission for respiratory disease, infection, seizure or trauma; RBC or platelet transfusion during PICU stay; respiratory, hematological, hepatic or renal dysfunction; severe sepsis/septic shock; renal replacement therapy).

\section{Patient outcomes after PICU discharge}

Children anemic at PICU discharge had a longer length of hospital stay after PICU discharge than non-anemic children (Table 4). Hospital mortality after PICU discharge did not differ between the two groups $(p=0.614)$. When analyzing the 386 children for whom an $\mathrm{Hb}$ level at hospital discharge was available, we found that a high proportion of children with anemia at PICU discharge were still anemic at hospital discharge (178/247, 72\%). Surprisingly $21 \%(29 / 139)$ of children who did not have anemia at PICU discharge developed anemia before hospital discharge.

The mean rate of $\mathrm{Hb}$ recovery between PICU and hospital discharge was $14.3 \pm 40 \mathrm{~g} / \mathrm{L} /$ week for the entire cohort; it was $18.5 \pm 39.7 \mathrm{~g} / \mathrm{L} /$ week for children anemic at PICU discharge and $6.7 \pm 39.5 \mathrm{~g} / \mathrm{L} /$ week for non-anemic children $(p<0.001)$

\section{Hemoglobin, transfusion and anemia at PICU admission, PICU discharge and hospital discharge}

Children anemic at PICU discharge already exhibited a lower median $\mathrm{Hb}$ at PICU admission as compared with children who were not anemic at PICU discharge, and this difference was still significant at hospital discharge (Fig. 2a). Children transfused with RBCs during their PICU stay had a lower median Hb at PICU admission than non-transfused children, but this difference was reduced (even though still significant) at PICU discharge and was no longer significant at hospital discharge (Fig. 2b).

The proportion of anemic children at PICU admission, PICU discharge and hospital discharge showed the same trend through the age categories: This proportion was highest in female adolescents and lowest in infants aged 1-5 months (Fig. 3). However, such an age-dependant variation is not in phase with the trend of the median $\mathrm{Hb}$ level through the age categories: The median $\mathrm{Hb}$ level was quite stable from one age category to another and did not significantly decrease in 1-5-month-old infants (Fig. 3).

\section{Discussion}

This observational study shows that anemia is frequent at PICU discharge (57\% of children included in our study). We identified two independent risk markers of anemia at PICU discharge: anemia at PICU admission (the strongest risk marker, showing an interaction with age) and admission after a non-cardiac surgery. A high proportion $(72 \%)$ of children discharged from PICU with anemia were still anemic at hospital discharge. Finally, the proportion of anemic children at PICU admission, PICU discharge and hospital discharge varied according to the age categories, while the median $\mathrm{Hb}$ level was quite stable through these age categories (Fig. 3).

\section{Anemia of PICU patients: from admission to hospital discharge... and beyond?}

Anemia is highly prevalent at PICU admission and incident during PICU stay [5]. Our study shows that this anemia of critical illness is not limited to the acute phase of the disease but is still a significant issue at PICU discharge and maybe even subsequently.

We found that anemia at PICU admission was the stronger predictor of anemia at PICU discharge. We also found that the strength of this association varied according to age. Several hypotheses may be raised to explain such an interaction: Causes of anemia may differ from one age category to another; the erythropoietic response may vary depending on age; nutritional and/or therapeutic supports may change from the neonatal period to adolescence and may be associated with a different course of anemia according to age.

Our data on anemia at hospital discharge are limited since the $\mathrm{Hb}$ level at hospital discharge was available for

Table 4 Outcomes after PICU discharge

\begin{tabular}{|c|c|c|c|c|c|}
\hline Outcome & All patients $(n=679)$ & Not anemic $(n=289)$ & Anemic $(n=390)$ & Univariate OR $\left(\mathrm{Cl}_{95} \%\right)$ & $p$ value \\
\hline $\begin{array}{l}\text { Hospital length of stay after PICU discharge, } \\
\text { median (Q1-Q3) }\end{array}$ & $5(2-13)$ & $4(2-9)$ & $6(3-15)$ & & $<0.001$ \\
\hline Death in hospital, $n(\%)^{\mathrm{a}}$ & $12(1.8)$ & $6(2.2)$ & $6(1.7)$ & $0.75(0.24,2.34)$ & 0.614 \\
\hline $\mathrm{Hb}$ at hospital discharge, median (Q1-Q3) & $109(97-124)$ & $124(111-136)$ & $102(92-117)$ & & $<0.001$ \\
\hline Anemia at hospital discharge $(n, \%)^{b}$ & $207(54)$ & $29(21)$ & $178(72)$ & $9.79(5.97,16.1)$ & $<0.001$ \\
\hline
\end{tabular}

Continuous variables are expressed as median (interquartile range)

$\mathrm{O}$ odds ratio, $\mathrm{Hb}$ hemoglobin, $\mathrm{Cl}$ confidence interval

a For children discharged alive from PICU

${ }^{\text {b }}$ Available for 386 children 
only 386 children. Keeping this limitation in mind, it is nevertheless noteworthy that $72 \%$ of children anemic at PICU discharge were still anemic when discharged from hospital. We do not have data on the Hb levels after hospital discharge. In a single-center Canadian cohort, 69\% (43/62) of children anemic at PICU discharge were still anemic at hospital discharge, but anemia resolved within 4-6 months in 28 patients who were subsequently followed up [11]. Bateman et al. studied 19 adult patients having left the ICU with an $\mathrm{Hb}<100 \mathrm{~g} / \mathrm{L}$ [10]; only $47 \%$ $(9 / 19)$ recovered from their anemia after 6 months of follow-up, with a median time to recovery of 11 weeks. In our study, the mean rate of $\mathrm{Hb}$ recovery between PICU and hospital discharge was $14.3 \pm 40 \mathrm{~g} / \mathrm{L} /$ week for the whole cohort; it was $18.5 \pm 39.7 \mathrm{~g} / \mathrm{L} /$ week for children anemic at PICU discharge and $6.7 \pm 39.5 \mathrm{~g} / \mathrm{L} /$ week for non-anemic children $(p<0.001)$. The rate usually encountered in healthy adults is $10 \mathrm{~g} / \mathrm{L} /$ week; to our knowledge, the rate of recovery in healthy children has not been established yet [10]. We do not know whether children included in our study received RBCs, iron or erythropoiesis-stimulating agents after PICU discharge: Thus, the rate of $\mathrm{Hb}$ recovery we observed cannot be properly interpreted, but it is possible that children anemic at PICU discharge exhibit a better erythropoietic reaction than their adult counterparts.

Our finding that $21 \%$ of children without anemia at PICU discharge developed anemia during the subsequent hospital stay is also of importance. Are the causes and consequences of this anemia occurring after PICU discharge the same as those of anemia persisting after PICU discharge? What follow-up strategies should be implemented at PICU discharge, if any? Further studies are clearly required to clarify the epidemiology of this "postPICU" anemia, to estimate the duration of this anemia and to better understand its mechanisms and its potential impacts.

\section{Is the usual age-based definition of anemia relevant in PICU?}

The WHO definition of anemia has been used in many studies. However, this definition has some limitations since it was established more than 40 years ago in a small population sample, without documentation of methodology [29]. Other diagnostic criteria have been proposed but none include pediatric criteria [30].

Studies on the distribution of normal $\mathrm{Hb}$ range in a healthy pediatric population are scarce and show quite variable results [31-33]. There is no universal definition of anemia in children. The normal range of $\mathrm{Hb}$ depends on several variables including age, race and socioeconomic status. The impact of age is largely explained by the transition from fetal $\mathrm{Hb}$ to adult $\mathrm{Hb}$ during the first weeks of life. This phenomenon, combined with a downregulation of EPO production related to the increase in blood oxygen content and tissue oxygenation delivery following birth, leads to the so-called physiologic anemia of infancy [34].

However, according to our results (Fig. 3), children admitted to PICU do not exhibit such an age-based fluctuation of $\mathrm{Hb}$ level. The usual age-based definitions of anemia are thus questionable in the PICU setting. We were surprised to find that the proportion of anemic children varied through the age categories (drop in 1-5-month-old infants) while the median $\mathrm{Hb}$ level was relatively constant. Our results raise the question of the appropriate $\mathrm{Hb}$ level to diagnose anemia in critically ill children: Further research is required to address this question.

\section{Red blood cell transfusions and anemia at PICU and hospital discharge}

Children included in our study were transfused according to a restrictive strategy, which recommends transfusion for stable non-cyanotic PICU patients only if their $\mathrm{Hb}$ level drops below $70 \mathrm{~g} / \mathrm{L}$. In the patients retained for our study, including unstable and cyanotic children, the mean $\mathrm{Hb}$ level before the first transfusion was $77.7 \pm 22.2 \mathrm{~g} / \mathrm{L}$ [19]. We do not know to what extent this restrictive RBC transfusion strategy may have impacted the $\mathrm{Hb}$ level at PICU discharge. It is plausible that a restrictive strategy increases the risk of anemia at PICU discharge. Indeed, in the Transfusion Requirements in Pediatric Intensive Care Unit study, the overall average lowest $\mathrm{Hb}$ concentration from randomization to PICU discharge was $87 \pm 4 \mathrm{~g} / \mathrm{L}$ in the restrictive group and $108 \pm 5 \mathrm{~g} / \mathrm{L}$ in the liberal group $(p<0.001)$, while the Hb levels were similar in these two groups at randomization $(80 \pm 10 \mathrm{~g} / \mathrm{L}$ versus $80 \pm 9 \mathrm{~g} / \mathrm{L})$ [35]. On the other hand, patients transfused with RBCs do not seem to exhibit a greater $\mathrm{Hb}$ level than non-transfused patients at (P)ICU discharge. Indeed, it has been shown in a large adult cohort study that the mean $\mathrm{Hb}$ difference between transfused and non-transfused patients was high at ICU admission but then decreased over time and becomes nonsignificant [2]. We observed the same trend in our study (Fig. 2b).

All in all, it seems that RBC transfusion during PICU stay is not a reliable tool to distinguish between children who will be anemic at PICU/hospital discharge and those who will not, even when a restrictive transfusion strategy is applied.

\section{Limitations and strengths}

Our study has several limitations. First, Hb levels at PICU and hospital discharge were collected retrospectively, which increases the risk of information bias. 
Second, the date of occurrence of the variables collected during the PICU stay was not documented, and the $\mathrm{Hb}$ we used to characterize anemia at PICU discharge could have been collected within the 7 days prior to discharge. It is thus theoretically possible that a variable considered as a risk marker of anemia at PICU discharge actually occurred after measurement of the discharge $\mathrm{Hb}$. However, we believe that the risk of such protopathic bias is reduced since the discharge $\mathrm{Hb}$ was collected the day before or on the day of PICU discharge in 628 out of the 679 included patients (92.5\%). Third, the $\mathrm{Hb}$ on the day of PICU discharge was not available for all patients, and we considered that a $\mathrm{Hb}$ level collected 1 to 7 days before PICU discharge should be a good surrogate of the $\mathrm{Hb}$ on the day of PICU discharge. This assertion could not be true and could result in information bias leading to an over- or underestimation of the prevalence of anemia at PICU discharge. However, as stated above, the vast majority of our patients had their last $\mathrm{Hb}$ collected the day before or on the day of PICU discharge. The risk of such information bias is thus significantly reduced. Fourth, we excluded 163 cases a posteriori that differed from the included cases; this may have induced a selection bias, which may limit the external validity of our study. Fifth, our study was single center, which also limits its external validity; however, our critical care unit is comparable to most multidisciplinary university-affiliated North American PICUs with regard to case mix and severity of illness. Sixth, our database has been collected in 2009-2010 and some practices may have changed since then, so that our study population may not appropriately reflect children discharged from PICU nowadays.

Our study has also several strengths. This is the first study that evaluates anemia at PICU discharge in a large cohort of critically ill children including neonates and children with congenital heart disease. We enrolled in this study all consecutive PICU admissions over a 1-year period, which resulted in a case mix with a limited risk of selection bias and no influence due to seasonal variation. Finally, all the independent variables were collected prospectively, which is a major asset to minimize information bias.

\section{Conclusions}

Anemia is frequent at PICU discharge and is strongly associated with anemia at PICU admission. While previous studies have focused on anemia at PICU admission and during PICU stay, it seems that the anemia of critically ill child is not limited to the acute phase of the critical illness: There seems to be a continuum of anemia from PICU admission to PICU discharge and hospital discharge.
As it is plausible that anemia at PICU discharge is associated with worse outcomes after PICU stay, efforts should be made to better understand its causes and consequences as well as to implement optimal care and follow-up strategies.

\section{Abbreviations \\ Cl: confidence interval; EPO: erythropoietin; Hb: hemoglobin; IL: interleu- kin; IQR: interquartile range; MODS: multiple organ dysfunction syndrome; OR: odds ratio; PELOD: pediatric logistic organ dysfunction; PICU: pediatric intensive care unit; PRISM: pediatric risk of mortality; RBC: red blood cell; WHO: World Health Organization.}

\section{Authors' contributions}

PD, SL, JL and MT designed the study; PD, AD and HB conducted data analysis and wrote the tables; PD, SL, JL, MT and OK contributed to data interpretation; PD wrote the manuscript except for "Statistical analysis" section which was written by $A D$ and $H B ; P D, S L, J L, M T, O K, A M$ and FL commented on the manuscript. All authors read and approved the final manuscript.

\section{Author details}

${ }^{1}$ Pediatric Intensive Care Unit, Department of Pediatrics, CHC, Liège, Belgium. ${ }^{2}$ Université de Lille, EA 2694 - Santé Publique: épidémiologie et qualité des soins, 59000 Lille, France. ${ }^{3}$ Pediatric Critical Care Unit, Geneva University Hospital, Geneva, Switzerland. ${ }^{4}$ Division of Pediatric Critical Care Medicine, Children's Hospital of Richmond at VCU, Richmond, VA, USA. ${ }^{5}$ Division of Pediatric Critical Care Medicine, Department of Pediatrics, Sainte-Justine Hospital, Université de Montréal, Montreal, Canada. ${ }^{6}$ Université de Lille, EA 2694 Santé Publique: épidémiologie et qualité des soins, Unité de Biostatistique, 59000 Lille, France. ${ }^{7}$ Pediatric Intensive Care Unit, CHU Lille, 59000 Lille, France.

\section{Acknowledgements}

The authors thank Nicole Poitras, Mariana Dumitrascu and Christian Dong for their support in the realization of this study.

\section{Competing interests}

The authors declare that they have no competing interests.

\section{Funding}

This study was supported by the Fonds de la Recherche en Santé du Québec (Grant \#24460).

\section{Publisher's Note}

Springer Nature remains neutral with regard to jurisdictional claims in published maps and institutional affiliations

Received: 25 January 2017 Accepted: 11 October 2017

Published online: 24 October 2017

\section{References}

1. Kassebaum NJ, Jasrasaria R, Naghavi M, Wulf SK, Johns N, Lozano R, et al. A systematic analysis of global anemia burden from 1990 to 2010. Blood. 2014;123(5):615-24

2. Corwin HL, Gettinger A, Pearl RG, Fink MP, Levy MM, Abraham E, et al. The CRIT study: anemia and blood transfusion in the critically ill-current clinical practice in the United States. Crit Care Med. 2004;32(1):39-52.

3. Vincent JL, Baron JF, Reinhart K, Gattinoni L, Thijs L, Webb A, et al. Anemia and blood transfusion in critically ill patients. JAMA. 2002:288(12):1499-507.

4. Thomas J, Jensen L, Nahirniak S, Gibney RT. Anemia and blood transfusion practices in the critically ill: a prospective cohort review. Heart Lung J Crit Care. 2010;39(3):217-25. 
5. Bateman ST, Lacroix J, Boven K, Forbes P, Barton R, Thomas NJ, et al. Anemia, blood loss, and blood transfusions in North American children in the intensive care unit. Am J Respir Crit Care Med. 2008;178(1):26-33.

6. Lacroix J, Demaret P, Tucci M. Red blood cell transfusion: decision making in pediatric intensive care units. Semin Perinatol. 2012;36(4):225-31.

7. Retter A, Wyncoll D, Pearse R, Carson D, McKechnie S, Stanworth S, et al. Guidelines on the management of anaemia and red cell transfusion in adult critically ill patients. Br J Haematol. 2013;160(4):445-64.

8. Walsh TS, Lee RJ, Maciver CR, Garrioch M, Mackirdy F, Binning AR, et al. Anemia during and at discharge from intensive care: the impact of restrictive blood transfusion practice. Intensive Care Med. 2006;32(1):100-9.

9. Walsh TS, Saleh EE, Lee RJ, McClelland DB. The prevalence and characteristics of anaemia at discharge home after intensive care. Intensive Care Med. 2006;32(8):1206-13.

10. Bateman AP, McArdle F, Walsh TS. Time course of anemia during six months follow up following intensive care discharge and factors associated with impaired recovery of erythropoiesis. Crit Care Med. 2009;37(6):1906-12.

11. Ngo QN, Matsui DM, Singh RN, Zelcer S, Kornecki A. Anemia among pediatric critical care survivors: prevalence and resolution. Crit Care Res Pract. 2013;2013:684361

12. Scott SP, Chen-Edinboro LP, Caulfield LE, Murray-Kolb LE. The impact of anemia on child mortality: an updated review. Nutrients. 2014;6(12):5915-32.

13. Chang S, Zeng L, Brouwer ID, Kok FJ, Yan H. Effect of iron deficiency anemia in pregnancy on child mental development in rural China. Pediatrics. 2013;131(3):e755-63.

14. Wormsbecker A, Sekhon MS, Griesdale DE, Wiskar K, Rush B. The association between anemia and neurological outcome in hypoxic ischemic brain injury after cardiac arrest. Resuscitation. 2017;112:11-6.

15. Bolge SC, Mody S, Ambegaonkar BM, McDonnell DD, Zilberberg MD. The impact of anemia on quality of life and healthcare resource utilization in patients with HIV/AIDS receiving antiretroviral therapy. Curr Med Res Opin. 2007;23(4):803-10.

16. Yohannes AM, Ershler WB. Anemia in COPD: a systematic review of the prevalence, quality of life, and mortality. Respir Care. 2011;56(5):644-52.

17. Burns JP, Sellers DE, Meyer EC, Lewis-Newby M, Truog RD. Epidemiology of death in the PICU at five U.S. teaching hospitals*. Crit Care Med. 2014;42(9):2101-8.

18. Needham DM, Davidson J, Cohen H, Hopkins RO, Weinert C, Wunsch $\mathrm{H}$, et al. Improving long-term outcomes after discharge from intensive care unit: report from a stakeholders' conference. Crit Care Med. 2012;40(2):502-9.

19. Demaret P, Tucci M, Ducruet T, Trottier H, Lacroix J. Red blood cell transfusion in critically ill children (CME). Transfusion. 2014;54(2):365-75.

20. Karam O, Lacroix J, Robitaille N, Rimensberger PC, Tucci M. Association between plasma transfusions and clinical outcome in critically ill children: a prospective observational study. Vox Sang. 2013;104(4):342-9.

21. World Health Organization: Haemoglobin concentrations for the diagnosis of anaemia and assessment of severity. Vitamin and Mineral Nutrition Information System. Geneva, World Health Organization, 2011 (WHO/ NMH/NHD/MNM/11.1) (http://www.who.int/vmnis/indicators/haemoglobin.pdf. Accessed 10 Sept 2015.

22. Behrman RE, Kliegman R, Jenson HB. Nelson textbook of pediatrics. 17th ed. Philadelphia, PA: Saunders; 2004. xlviii, 2618 p.

23. Pollack MM, Ruttimann UE, Getson PR. Pediatric risk of mortality (PRISM) score. Crit Care Med. 1988;16(11):1110-6.
24. Leteurtre S, Martinot A, Duhamel A, Proulx F, Grandbastien B, Cotting J, et al. Validation of the paediatric logistic organ dysfunction (PELOD) score: prospective, observational, multicentre study. Lancet. 2003;362(9379):192-7.

25. Goldstein B, Giroir B, Randolph A. International pediatric sepsis consensus conference: definitions for sepsis and organ dysfunction in pediatrics. Pediatr Crit Care Med. 2005;6(1):2-8.

26. Corwin HL. Anemia and blood transfusion in the critically ill patient: role of erythropoietin. Crit Care. 2004;8(Suppl 2):S42-4.

27. Hayden SJ, Albert TJ, Watkins TR, Swenson ER. Anemia in critical illness: insights into etiology, consequences, and management. Am J Respir Crit Care Med. 2012;185(10):1049-57 PubMed PMID: 22281832

28. Lasocki S, Longrois D, Montravers P, Beaumont C. Hepcidin and anemia of the critically ill patient: bench to bedside. Anesthesiology. 2011;114(3):688-94.

29. Cappellini MD, Motta I. Anemia in clinical practice-definition and classification: does hemoglobin change with aging? Semin Hematol. 2015:52(4):261-9.

30. Beutler E, Waalen J. The definition of anemia: what is the lower limit of normal of the blood hemoglobin concentration? Blood 2006;107(5):1747-50

31. Sherriff A, Emond A, Hawkins N, Golding J. Haemoglobin and ferritin concentrations in children aged 12 and 18 months. ALSPAC Children in Focus Study Team. Arch Dis Child. 1999;80(2):153-7.

32. Jopling J, Henry E, Wiedmeier SE, Christensen RD. Reference ranges for hematocrit and blood hemoglobin concentration during the neonatal period: data from a multihospital health care system. Pediatrics. 2009;123(2):e333-7.

33. Stevens GA, Finucane MM, De-Regil LM, Paciorek CJ, Flaxman SR, Branca F, et al. Global, regional, and national trends in haemoglobin concentration and prevalence of total and severe anaemia in children and pregnant and non-pregnant women for 1995-2011: a systematic analysis of population-representative data. Lancet Glob Health. 2013;1(1):e16-25.

34. Widness JA. Pathophysiology of anemia during the neonatal period, including anemia of prematurity. NeoReviews. 2008;9(11):e520.

35. Lacroix J, Hebert PC, Hutchison JS, Hume HA, Tucci M, Ducruet T, et al. Transfusion strategies for patients in pediatric intensive care units. N Engl J Med. 2007;356(16):1609-19.

36. McEvoy MT, Shander A. Anemia, bleeding, and blood transfusion in the intensive care unit: causes, risks, costs, and new strategies. Am J Crit Care Off Publ Am Assoc Crit Care Nurses. 2013;22(6 Suppl):eS1-13.

37. Algarin C, Nelson CA, Peirano P, Westerlund A, Reyes S, Lozoff B. Irondeficiency anemia in infancy and poorer cognitive inhibitory control at age 10 years. Dev Med Child Neurol. 2013;55(5):453-8.

38. Dlugaj M, Winkler A, Weimar C, Durig J, Broecker-Preuss M, Dragano N, et al. Anemia and mild cognitive impairment in the german general population. J Alzheimer's Dis JAD. 2015;49(4):1031-42.

39. Milman N. Postpartum anemia I: definition, prevalence, causes, and consequences. Ann Hematol. 2011;90(11):1247-53.

40. Farag YM, Keithi-Reddy SR, Mittal BV, Surana SP, Addabbo F, Goligorsky MS, et al. Anemia, inflammation and health-related quality of life in chronic kidney disease patients. Clin Nephrol. 2011;75(6):524-33.

41. Adams KF Jr, Pina IL, Ghali JK, Wagoner LE, Dunlap SH, Schwartz TA, et al. Prospective evaluation of the association between hemoglobin concentration and quality of life in patients with heart failure. Am Heart J. 2009;158(6):965-71. 